\title{
ANTIGEN-INDUCED ELEVATION OF CYCLIC GMP LEVEL IN PLASMA AND ITS ABOLITION IN EXPERIMENTALLY IMMUNOSUP- PRESSIVE MICE
}

\author{
ITARU YAMAMOTO AND NORIO ISHII
}

Department of Medicinal Biochemistry, Faculty of Pharmaceutical Sciences, Okayama University, Tsushimanaka 1-1-1, Okayama

(Received December 12, 1981)

Intravenous injection of antigenic dose of sheep erythrocytes (SRBC)* into mice caused a 150-200\% increase in plasma cyclic GMP level within 5 min which continued for $60 \mathrm{~min}$ thereafter. Immunization by soluble antigens such as dextran sulfate and bovine serum albumin also elevated cyclic GMP level in plasma. The plasma cyclic GMP increased by antigen stimulation might be derived from immunocompetent cells. This assumption was supported by several lines of evidence as follows: (1) rat erythrocytes which are less antigenic for mice caused a relatively low response in terms of increase in cyclic GMP compared with SRBC, (2) this cyclic GMP response was abrogated in animals under immunosuppressive states where X-irradiated, azathioprine-treated or tumor-bearing mice were used. Mice pretreated with agents which block autonomic nervous system functions develop normal plasma cyclic GMP responses upon SRBC injection. Our observation in this report and many in vitro studies by other investigators suggested that plasma cyclic GMP elevated by antigen stimulation may be mainly derived from lymphoid cells as a consequence of the triggering of immune response. response

Keywords-SRBC; plasma cyclic GMP; immunosuppression; PFC; immune

\section{INTRODUCTION}

It has been widely documented in recent years that cyclic nucleotides (cyclic AMP and cyclic GMP) are possibly involved in immune responses. ${ }^{1)}$ It was originally reported by Hadden et al. ${ }^{2)}$ that optimal mitogenic concentration of PHA or Con A produced 10- to 50-fold elevation in lymphocyte cyclic GMP level within $20 \mathrm{~min}$ of exposure to these mitogens. Watson ${ }^{3)}$ reported that the addition of LPS to mouse spleen cell culture induced rapid and transient increase in the intracellular cyclic GMP level, but not cyclic AMP. Furthermore, Weinstein et al ${ }^{4)}$ demonstrated that exogenous cyclic GMP and its deriva- tives could stimulate resting mouse spleen lymphocytes in culture to synthesize RNA and DNA, with a time course similar to that caused by Con $A$. Based on these results, it has been proposed that endogenous cyclic GMP acts as an intracellular mediator of the proliferative response to mitogens. In relation to these in vitro observation, Yamamoto and $\mathrm{Webb}^{5)}$ previously showed that mice injected intravenously with SRBC demonstrated a transient increase in splenic cyclic AMP level (4-fold) which peaked at $2 \mathrm{~min}$, and continuous increase in splenic cyclic GMP level (1.5-fold) which occurred beginning 5-10 min after injection.

\footnotetext{
* Abbreviations used in this paper: cyclic AMP, adenosine 3',5'-cyclic monophosphate; cyclic GMP, guanosine 3', $5^{\prime}$-cyclic monophosphate; SRBC, sheep erythrocytes; RRBC, rat erythrocytes; BSA, bovine serum albumin; PFCs, plaque forming cells; EDTA, ethylenediamine tetraacetic acid; PHA, phytohemagglutinin; Con A, concanavalin A; PWM, pokeweed mitogen.
} 
There are several reports that the administration of hormones or neurotransmitters to experimental animals and human subjects results in a sharp increase in plasma level of cyclic nucleotide. ${ }^{6)}$ Since the cyclic nucleotide level in plasma is in a dynamic steady-state relation with its intracellullar pools and is usually kept low, a slight increase of these nucleotides in tissue would be expected to result in a significant increase in extracellular fluids. ${ }^{6 a, b, 7)}$

Based on these findings, we decided to investigate the effects of in vivo antigenic stimulation on plasma cyclic GMP levels.

\section{MATERIALS AND METHODS}

Animals - ddY male mice (6-8 weeks of age) and Sprague-Dawley strain of male rats (6-8 weeks of age) were used in these studies.

Antigens - Sheep erythrocytes were purchased from Nishinihon Sheep Farm (Hiroshima, Japan). The SRBC were washed three times in normal saline prior to injection. Bovine serum albumin was obtained from Sigma (St. Louis, Mo). Dextran sulfate (MDS Kowa Injection) was purchased from Kowa Co., Ltd. (Nagoya, Japan). Rat erythrocytes were purified from heparinized blood by Ficoll-Conray sedimentation and washed three times in normal saline prior to use. All antigens were dissolved or suspended in normal saline and intravenously injected into the tail vein of mice.

Reagents - Azathioprine and propranolol hydrochloride (Inderal Injectable) were kindly supplied from Tanabe Seiyaku Co., Ltd. (Osaka, Japan) and from Sumitomo Chemical Industry (Osaka), respectively. Phenoxybenzamine was obtained from Tokyo Chemical Industry Co., Ltd. (Tokyo, Japan). Atropine was purchased from Nakarai Chemicals, Ltd. (Kyoto, Japan) and hexamethonium chloride from Wako Chemical Industries, Ltd. (Osaka). Ficoll 400 was purchased from Pharmacia Fine Chemicals (Uppsala, Sweden) and Conray 400 was purchased from Daiichi Seiyaku Co., Ltd. (Tokyo). Heparin sodium (Injectable) was obtained from Shimizu Seiyaku Co., Ltd. (Osaka). Cyclic GMP radioim- munoassay kits were generously donated by Yamasa Shoyu Co., Ltd. (Chiba, Japan). Other reagents were of analytical grade from the commercial sources.

Treatment of Animals - Sarcoma-180 was kindly donated from Chugai Seiyaku Co., Ltd. (Tokyo). Experimental mice were sensitized against sarcoma-180 cells from ascites of donor mice by intraperitoneal inoculation with $5 \times 10^{6}$ cells $10 \mathrm{~d}$ prior to the experiment. Irradiated mice were obtained by the systemic X-ray irradiation (600 or $300 \mathrm{R}) 12 \mathrm{~h}$ prior to the experiment.

Antigen Administration and Sample Collection - Mice were intravenously injected with an appropriate antigen in $0.2 \mathrm{ml}$ solution or suspen-

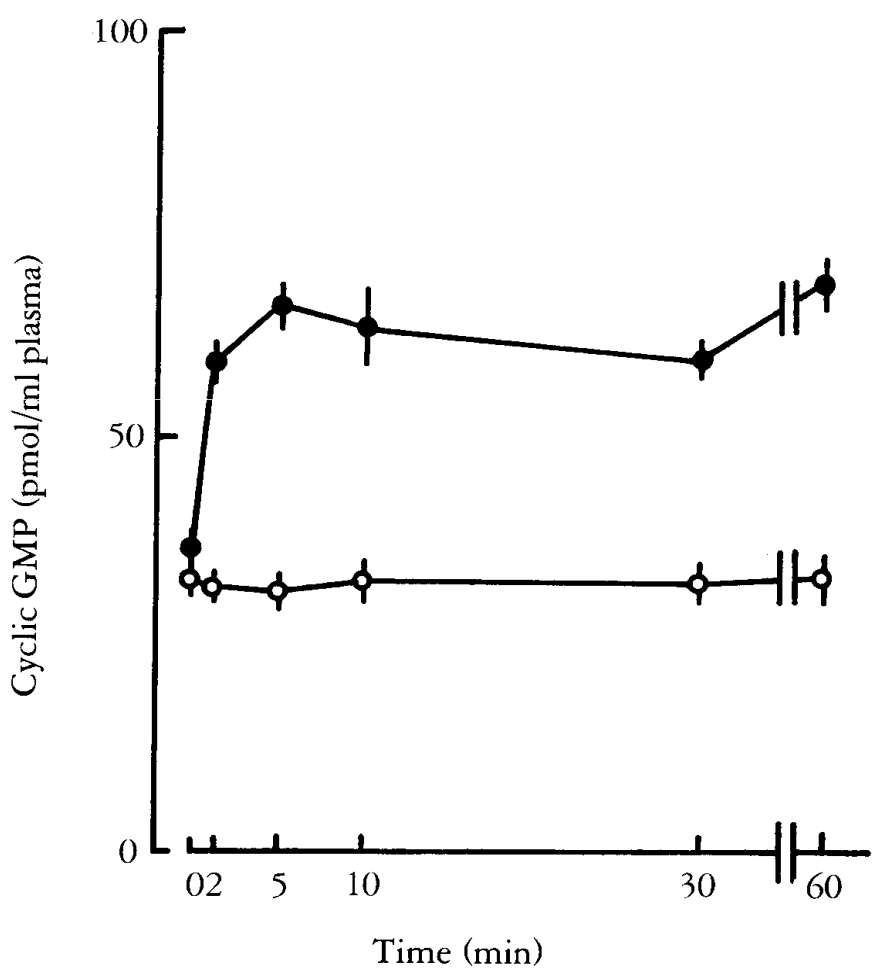

FIG. 1. Effect of Intravenous Injection of SRBC on Plasma Cyclic GMP Levels in Mice

Groups of mice were given intravenously either $3 \times 10^{8}$ SRBC in $0.2 \mathrm{ml}$ normal saline (O) or normal saline alone $(O)$ and sacrificed at indicated times. The plasma samples were obtained and the concentrations of cyclic GMP were determined in duplicate. Each point represents the mean $\pm S E$ of 4 mice. 
sion and sacrificed by decapitation at the indicated time. Whole blood from mouse was mixed quickly with $0.01 \mathrm{ml}$ of normal saline containing $500 \mathrm{~mm}$ EDTA. After centrifugation, an aliquote

TABLE I. Effects of Different Types of Antigens on Plasma Cyclic GMP Level in Mice

\begin{tabular}{lc}
\hline \hline \multicolumn{1}{c}{ Antigens } & $\begin{array}{c}\text { Plasma cyclic GMP } \\
\text { (pmol per ml) }\end{array}$ \\
\hline Saline control & $62.8 \pm 5.8$ \\
SRBC $\left(3 \times 10^{8}\right)$ & $98.5 \pm 2.0$ \\
Dextran sulfate & \\
$\quad(50 \mathrm{mg} / \mathrm{kg})$ & $96.0 \pm 5.5$ \\
BSA $(0.5 \mathrm{mg} / \mathrm{kg})$ & $71.0 \pm 1.4$ \\
Saline control & $43.0 \pm 5.4$ \\
SRBC $\left(3 \times 10^{8}\right)$ & $80.3 \pm 5.0$ \\
RRBC $\left(3 \times 10^{8}\right)$ & $60.0 \pm 9.3$ \\
\hline
\end{tabular}

Groups of mice were immunized intravenously with different types of in $0.2 \mathrm{ml}$ of saline or saline alone. The mice sacrificed 5 min after the immunizations and the plasma concentrations of cyclic GMP were determined. Each value represents the mean $\pm S E$ of 4 mice.
$(50-100 \mu \mathrm{l})$ of the supernatant was directly assayed for cyclic GMP.

Measurement of Plasma Cyclic GMP-The assay of plasma cyclic GMP was carried out using commercially available radioimmunoassay kits. ${ }^{8)}$

Measurement of Anti-SRBC Antibody Forming Cells - Animals were sacrificed $4 \mathrm{~d}$ after SRBC immunization (i.v.) and splenic direct plaque forming cells (PFC) were determined according to the method of Jerne and Nordin with modification. ${ }^{9}$

\section{RESULTS}

Effects of Antigens on the Plasma Concentration of Cyclic GMP

The concentration of plasma cyclic GMP was increased by $150-200 \%$ in $5 \mathrm{~min}$ after the intravenous injection of antigenic doses of SRBC into mice (Fig. 1). This elevation was continued until $60 \mathrm{~min}$ post-injection. No significant changes in plasma cyclic GMP level were observed during these periods in control mice which received normal saline. Since we previously established that the increase of splenic cyclic nucleotides are caused by SRBC, a particulate anti-

TABLE II. Effects of Intravenous Injection of SRBC on Plasma Cyclic GMP Levels in Normal and Irradiated Mice

\begin{tabular}{|c|c|c|c|}
\hline Expt. No. & Irradiation & SRBC & Plasma cyclic GMP (pmol $/ \mathrm{ml})$ \\
\hline \multirow[t]{6}{*}{ I } & & - & $48 \pm 10.0$ \\
\hline & & + & $97 \pm 8.0$ \\
\hline & & - & $46 \pm 4.5$ \\
\hline & $300 \mathrm{~K}$ & + & $45 \pm 3.8$ \\
\hline & $600 \mathrm{R}$ & - & $52 \pm 9.5$ \\
\hline & (1) & + & $63 \pm 13.7$ \\
\hline \multirow[t]{6}{*}{ II } & 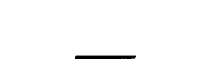 & - & $52 \pm 6.9$ \\
\hline & & + & $73 \pm 4.9$ \\
\hline & $300 \mathrm{R}$ & - & $57 \pm 6.6$ \\
\hline & $300 \mathrm{~K}$ & + & $55 \pm 9.3$ \\
\hline & $600 \mathrm{R}$ & - & $56 \pm 5.9$ \\
\hline & $000 \mathrm{n}$ & + & $58 \pm 7.6$ \\
\hline
\end{tabular}

Irradiation was performed $24 \mathrm{~h}$ before immunization. Groups of mice were immunized intravenously with $3 \times 10^{8} S R B C$ or saline. The mice were sacrificed 5 min after the immunization and the plasma concentrations of cyclic GMP were determined. Each value represents the mean $\pm S E$ of 4 mice. 
gen, but not caused by soluble antigens such as $\mathrm{BSA}{ }^{5)}$ experiments were performed using soluble antigens such as dextran sulfate and BSA. As shown in Table I, both dextran sulfate and BSA induced a significant elevation of plasma cyclic GMP concentration at $5 \mathrm{~min}$ after the intravenous injection. To determine whether anti-

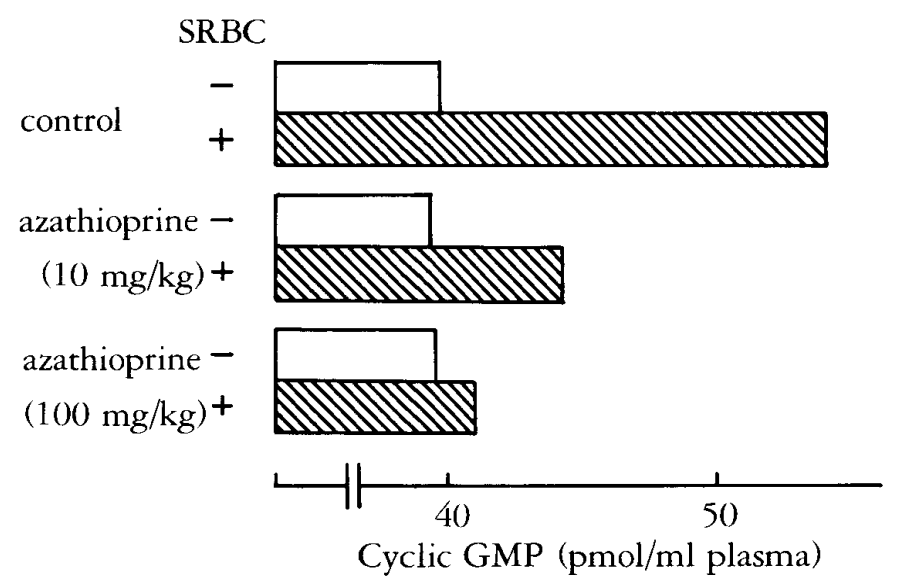

FIG. 2. Inhibiting Effect of Azathioprine Treatment on the Increase of Plasma Cyclic GMP Levels induced by SRBC in Mice

Mice were daily administered intraperitoneally with azathioprine (10 or $100 \mathrm{mg} / \mathrm{kg}$ ) for three days. On the next day after the last administration, SRBC $\left(3 \times 10^{8}\right)$ were injected intravenously into those mice and sacrificed 5 min later. genicity might be essential for this plasma cyclic GMP response, groups of mice were given rat erythrocytes (RRBC) which are less antigenic to mice. RRBC $\left(3 \times 10^{8}\right.$ cells $)$ caused, in fact, an elevation of plasma cyclic GMP level, but it was quite low (1.4-fold) in response as compared to that by the same dose of SRBC (1.7-fold) (see Table I).

$S R B C$-induced Change in Plasma Cyclic GMP in immunologically Defected Mice

If cyclic GMP elevated in plasma was derived from immunocompetent cells, it would be expected that the slight or no augmentation of plasma cyclic GMP by antigen stimulation should occur in immunosuppressive states. As shown in Table II, no elevation of cyclic GMP in plasma was observed, when SRBC was injected into mice which received a lethal $(600 \mathrm{R})$ or a sublethal $(300 \mathrm{R})$ dose of X-ray irradiation.

Next, the effect of treatment with an immunosuppressive drug, azathioprine on the SRBC-induced elevation of plasma cyclic GMP was examined. Mice were daily administered intraperitoneally with azathioprine suspended in $0.3 \%$ arabic gum at the dose of $10 \mathrm{or} 100 \mathrm{mg} / \mathrm{kg}$ for $3 \mathrm{~d}$ before SRBC injection. On the next day after the last administration, SRBC $\left(3 \times 10^{8}\right.$ cells $)$ were injected intravenously into those mice and sacrificed 5 min later. Control mice were treated with $0.3 \%$ arabic gum for $3 \mathrm{~d}$. As depicted in Fig.

TABLE III. Correlation between PFC Formation and SRBC-induced Increase in Plasma Cyclic GMP Levels in Normal and Sarcoma-180-bearing Mice

\begin{tabular}{ccccc}
\hline \hline Condition & PFC $/ 10^{6}$ cells & PFC $\left(\times 10^{3}\right) /$ spleen & SRBC & $\begin{array}{c}\text { Plasma cyclic GMP } \\
\text { (pmol per ml })\end{array}$ \\
\hline $\begin{array}{c}\text { Normal (intact) } \\
\text { mice }\end{array}$ & $4261 \pm 336$ & $2253 \pm 778$ & - & $49 \pm 4.2$ \\
$\begin{array}{c}\text { Sarcoma-180- } \\
\text { bearing mice }\end{array}$ & $96 \pm 43$ & $175 \pm 77$ & - & $75 \pm 27.1$ \\
\hline
\end{tabular}

Both normal and tumor-bearing mice were separated into two groups for the PFC responses and plasma cyclic GMP assays. In the former experiment, mice were immunized intravenously with $2 \times 10^{8} S R B C$ and sacrificed $4 d$ after the immunization and then splenic PFCs were determined. In the latter experiment, mice were injected intravenously with $3 \times 10^{8} S R B C$ or saline and sacrificed 5 min after the injection and the plasma cyclic GMP concentrations were determined. Each value represents the mean \pm SE of 4 animals. 
2, a suppression of plasma cyclic GMP increase was observed in the azathioprine-treated mice in a dose-dependent manner.

The third experiment of this type was performed to compare the antigen-induced cyclic GMP response in normal and tumor-bearing mice. It has been well recognized that mice bearing various transplantable tumors show a suppressed immune response following antigenic stimulation. ${ }^{10)}$ We employed sarcoma-180 (ascites form) which was maintained by serial intraperitoneal transplantation into ddY mice. Tumor-bearing group of mice were intraperitoneally inoculated with $5 \times 10^{6}$ sarcoma-180 cells $10 \mathrm{~d}$ prior to the experiment. On the day of the experiment, both normal and tumor-bearing mice were challenged intravenously with $3 \times 10^{8}$ SRBC and the plasma cyclic GMP concentration was determined at 0 or $5 \mathrm{~min}$ after antigen administration. Direct splenic PFC formation of each group of mice was also assessed as follows: Mice were immunized with $2 \times 10^{8}$ SRBC $6 \mathrm{~d}$ after sensitization with $5 \times 10^{6}$ sarcoma- 180 cells. On day 10 (4 d after SRBC immunization), splenic anti-SRBC IgM antibody forming cells were measured by the hemolytic plaque assay. As summarized in Table III, the SRBC-induced plasma cyclic GMP response was completely inhibited in tumor-bearing mice where a substantial decrease in number of PFC was observed.

The Effect of Agents which block Autonomic Nervous System on Antigen Induced Plasma Cyclic GMP saline control

$\operatorname{SRBC}\left(3 \times 10^{8}\right)$

phenoxybenzamine $(2 \mathrm{mg} / \mathrm{kg})+\mathrm{SRBC}$

propranolol $(10 \mathrm{mg} / \mathrm{kg})+\mathrm{SRBC}$

saline control

$\operatorname{SRBC}\left(3 \times 10^{8}\right)$

atropine $(1 \mathrm{mg} / \mathrm{kg})+\mathrm{SRBC}$

hexamethonium $(0.5 \mathrm{mg} / \mathrm{kg})+\mathrm{SRBC}$

BSA $(0.5 \mathrm{mg} / \mathrm{kg})$

phenoxybenzamine $(2 \mathrm{mg} / \mathrm{kg})+\mathrm{BSA}$

propranolol $(10 \mathrm{mg} / \mathrm{kg})+\mathrm{BSA}$
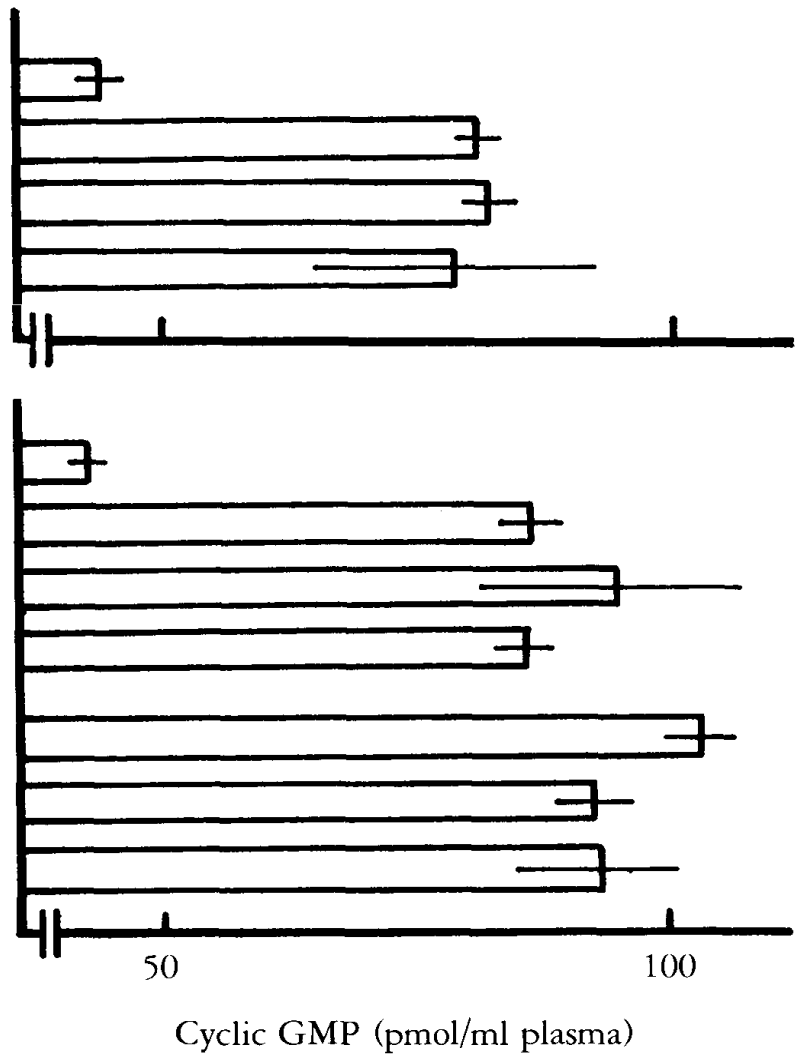

Cyclic GMP (pmol/ml plasma)

FIG. 3. Effects of Adrenergic, Cholinergic and Ganglionergic Blockers on Antigen-induced Increases of Plasma Cyclic GMP Levels in Mice

Phenoxybenzamine, propranolol and atropine were intraperitoneally injected $2 h$ before and hexamethonium $1 \mathrm{~h}$ before antigens at the dose indicated. Mice were sacrificed 5 min after antigen treatments. Each bar delineates mean $\pm S E$. 


\section{Increase}

Our previous report has shown that the biosynthesis of cyclic nucleotides in certain tissue may be regulated by the autonomic nervous system, ${ }^{11)}$ thus it seemed relevant to examine whether this antigen-induced increase in plasma cyclic GMP may be also under the influence of autonomic nervous system. Therefore, we investigated the effect of $\alpha$ - and $\beta$-adrenergic, cholinergic and ganglionergic blocking agents on the plasma cyclic GMP response. Groups of mice were intraperitoneally treated $2 \mathrm{~h}$ prior to antigen injection with either phenoxybenzamine (2 $\mathrm{mg} / \mathrm{kg})$, propranolol $(10 \mathrm{mg} / \mathrm{kg})$ or atropine (1 $\mathrm{mg} / \mathrm{kg}$ ), and $1 \mathrm{~h}$ prior to antigen with hexamethonium $(0.5 \mathrm{mg} / \mathrm{kg})$. The results are presented in Fig. 3. These drugs showed no significant effect on antigen-induced increase in plasma cyclic GMP. In this study the influences of these blockers themselves on plasma levels of cyclic GMP were examined and it was confirmed that none of them significantly changed the nucleotide levels in mice (data not shown).

\section{DISCUSSION}

We have demonstrated in this report that both particulate and soluble antigens caused significant increases (1.5-2.0-fold) in plasma cyclic GMP level in mice. However, this antigen-induced elevation of plasma cyclic GMP was abolished in animals under various immunosuppressive states where X-irradiated, azathioprine-treated or sarcoma-180-bearing mice were used.

Over the last 10 years, many investigators have presented evidence that endogenous cyclic GMP might act as an intracellular mediator of the proliferative response to mitogens in vitro. ${ }^{1)}$ On the other hand, there are two major difficulties in studying the in vivo role of endogenous cyclic GMP in the induction of immune response after antigenic stimulation although there is a report by Yamamoto and $\mathrm{Webb}^{5)}$ demonstrating that both cyclic AMP and cyclic GMP were increased in spleen cells after intravenous injection of SRBC into mice: (1) Antigen-reactive lymphocytes are a minority of the population, so that it is difficult to detect a change of cyclic GMP in lymphoid cells, (2) it would be difficult to identify which tissues or cell populations contribute to such cyclic GMP elevation. Since the plasma levels of cyclic nucleotides which is usually low is in an a dynamic steady-state relation with its intracellular pools, a slight elevation of these nucleotides in tissues would be expected to cause a significant increase in plasma. ${ }^{6 a, b, 7)}$ In fact, it has been proposed that assay of plasma cyclic nucleotides following exposure to the hormones, neurotransmitters or other agents was very promising as a test for various bodily functions in experimental and clinical studies. ${ }^{12)}$ We have found that antigens cause an increase in plasma cyclic GMP level without any apparent influence of cholinergic regulation. The assumption that this plasma cyclic GMP responses induced by various antigens are derived largely from immunocompetent cells is supported by several lines of evidence as follows: (1) Less antigenic PRBC caused a lower elevation of plasma cyclic GMP level, (2) SRBC-induced plasma cyclic GMP increase was completely inhibited in irradiated, azathioprine-treated or sarcoma-180 tumor-bearing mice where immunes are suppressed. Ohara et al. ${ }^{13)}$ suggested that peripheral blood lymphocytes from patients with common variable immunodeficiency did not show any increase or cyclic GMP by PWMstimulation. This in vitro observation strongly correlates with our in vivo findings presented here.

We have demonstrated that the intravenous injection of SRBC into mice produced the plasma levels of both cyclic GMP and cyclic AMP. The increase of cyclic GMP was observed not only in normal (intact) mice, but also in adrenalectomized ones. However, the significant change in cyclic AMP was observed only in normal mice (manuscript in preparation). These results and other findings that exogenous administration of catecholamine(s) increase the plasma levels of cyclic AMP in rats $^{12 a}$ ) would suggest that the release of catecholamine(s) plays an important role in the elevation of cyclic AMP by antigen stimulation.

In this experiment, we could detect the change 
in plasma cyclic GMP after the injection of soluble antigen such as BSA and dextran sulfate as well as particulate antigens, into mice. In our earlier report, ${ }^{5)}$ we had not been able to demonstrate any changes in splenic cyclic nucleotides in mice following injection of a soluble antigen, dextran sulfate. It is possible to suggest that this is due to different kinetics of antigen processing or slower and more gradual interaction with relevant antigen-sensitive $\mathrm{T}$ - and B-cells.

At present, we do not have any direct evidence as to which population of lymphoid cells (macrophage, $\mathrm{T}$ or $\mathrm{B}$ cells) produces the cyclic GMP. Our data, however, are compatible with the hypothesis that increased plasma cyclic GMP levels induced by antigen may be derived from lymphoid cells and represent a positive signal in the development of in vivo immune responses. In conclusion, the present experiments showed that there might be a good correlation between the plasma cyclic GMP elevation and immunological states in vivo. Therefore, it would be expected that the determination of plasma cyclic GMP after an appropriate antigen injection would serve as a diagnostic tool for testing immunological condition in subjects with immunological defects.

\section{REFERENCES}

1) J.W.Hadden: "Comprehensive Immunology," Vol. 3, ed. by J.W.Hadden, R.G.Coffey and F.Spreafico, Plenum Press, New York, 1977, pp. 1-28.

2) J.W.Hadden, E.W.Hadden, M.K.Haddox and N.P.Goldberg: Guanosine 3',5'-cyclic monophosphate: A possible intracellular mediator of mitogenic influences in lymphocytes, Proc. Nat. Acad. Sci. U.S.A., 69, 3024-3027 (1972).

3) J.Watson: The influence of intracellular levels of cyclic nucleotides on cell proliferation and the induction of antibody synthesis, J. Exp. Med., 141, 97-111 (1975).

4) Y.Weinstein, D.A.Chambers, H.R.Bourne and K.L.Melmon: Cyclic GMP stimulates lymphocyte nucleic acid synthesis, Nature, 251, 352-353 (1974).

5) I.Yamamoto and D.R.Webb: Antigen-stimulated changes in cyclic nucleotide levels in the mouse, Proc. Nat. Acad. Sci. U.S.A., 72, 2320-2324 (1975).

6) a) A.E.Broadus, N.I.Kaminsky, R.C.Northcutt, E.W.Hardman, E.W.Sutherland and G.W.Liddle: Effects of glucagon on adenosine $3^{\prime}, 5^{\prime}$-monophosphate and guanosine $3^{\prime}, 5^{\prime}$-monophosphate in human plasma and urine, J. Clin. Invest., 49, $2237-2245$ (1970); b) N.I.Kaminsky, A.E.Broadus, J.G.Hardman, P.J.Jones, J.H.Ball, E.W.Sutherland and G.E.Liddle: Effects of parathyroid hormone on plasma and urinary adenosine 3',5'-monophosphate in man, J. Clin. Invest., 49, 2387-2395 (1970); c) J.H.Ball, N.I.Kaminsky, J.G.Hardman, A.E.Broadus, E.W.Sutherland and G.W.Liddle: Effects of catecholamines and adrenergicblocking agents on plasma and urinary cyclic nucleotides in man, J. Clin. Invest., 51, 2124-2129 (1972); d) A.Peytremann, W.D.Nicholson, J.G. Hardman and G.W.Liddle: Effect of adrenocorticotrophic hormone on extracellular adenosine $3^{\prime}, 5^{\prime}$ monophosphate in the hypophysectomized rat, Endocrinology, 92, 1502-1506 (1973); e) J.E. Liljenquist, J.D.Bomboy, S.B.Lewis, B.C. Sinclair-Smith, P.W.Felts, W.W.Lacy, O.B.Crofford and G.W.Liddle: Effects of glucagon on net splanchnic cyclic AMP production in normal and diabetic man, J. Clin. Invest., 53, 198-204 (1974); f) R.C.Strange and D.O.Mjøs: The sources of plasma cyclic AMP: Studies in the rat using isoprenaline, nicotinic acid and glucagon, J. Clin. Invest. , 5, 147-152 (1975); g) Y.Saitoh, S.Morita, Y.Irie and H.Kohri; Evaluation of a new $\beta$-adrenergic blocking agent, carteolol, based on metabolic responses in rats. II. Blockade by carteolol of the epinephrineand isoproterenol-induced increases of tissue and blood cyclic AMP in vivo, Biochem. Pharmacol., 25, $1843-1849$ (1976).

7) A.E.Broadus, N.I.Kaminsky, J.G.Hardman, E.W.Sutherland and G.W.Liddle: Kinetic parameters and renal clearance of plasma adenosine $3^{\prime}, 5^{\prime}$ monophosphate and guanosine 3',5'-monophosphate in man, J. Clin. Invest., 49,2222-2236 (1970).

8) M.Honma, T.Satoh, J.Takezawa and M.Ui: An ultrasensitive method for the simultaneous determination of cyclic AMP and cyclic GMP in small-volume samples from blood and tissue, Biochem. Med., 18, $257-273$ (1977).

9) N.K.Jerne and A.A.Nordin: Plaque formation in agar by single antibody-forming cells, Science, 140, 405 (1963).

10) a) R.E.McCarthy: Modification of the immune response of mice to skin homografts and heterografts by Ehrlich ascites carcinoma, Cancer Res., 24, 915-919 (1964); b) Y.Nakayama, T.Hamaoka and M.Kitagawa: Antibody response to tumor-bearing animals. IV. Mechanism of immunosuppression in tumor-bearing state, Proc. Jap. Cancer Ass., 26, 259 (1967); c) R.E.McCarthy, J.M.Coffin and S.L.Gates: Selective inhibition of the secondary immune response to mouse skin allografts by cell-free Ehrlich ascites carcinoma fluid, Transplantation, 6, 737-743 (1968); d) I.Kamo and N.Ishida: Immune response in tumorbearing mice, Gann., 62, 453-458 (1971); e) 
P.Mocarelli, M.L.Villa, G.Garotta, C.Porta, G.Bigi and E.Clerici: Reversibility of immunosuppression due to Ehrlich ascites carcinoma, J. Immunol., 111, 973-975 (1973); f) S.Zolla, D.Naor and P.Tanapatchaiyapong: Cellular basis of immunodepression in mice with plasmacytomas, J. Immunol., 112, 2068-2076 (1974).

11) A.E.Broadus: "Advances in Cyclic Nucleotide Research," Vol. 8, ed. by P.Greengard and G.A.Robison, Raven Press, New York, 1977, pp. 509-549.

12) a) S.Kunitada, M.Honma and M.Ui: Increases in plasma cyclic AMP dependent on endogenous catecholamines, Eur. J. Pharmacol., 48, 159-169 (1978); b) S.Kunitada and M.Ui: The plasma cyclic AMP response to catecholamines as potentiated by phentolamine in rat, Eur. J. Pharmacol., 49, 169 (1978); c) M.Honma and M.Ui: Plasma cyclic GMP:Response to cholinergic agents, Eur. J. Pharmacol. , 47, 1-10 (1978).

13) J.Ohara, T.Kishimoto and Y.Yamamura: In vitro immune response of human peripheral lymphocytes. III. Effect of anti- $\mu$ or anti- $\delta$ antibody on PWMinduced increase of cyclic nucleotides in human B lymphocytes, J. Immunol. , 121, 2088-2096 (1978). 